\title{
Erratum to: Non-Native Plants Disrupt Dual Promotion of Native Alpha and Beta Diversity
}

\section{Tadashi Fukami • Peter J. Bellingham •}

Duane A. Peltzer • Lawrence R. Walker

(C) Institute of Botany, Academy of Sciences of the Czech Republic 2014

\section{Erratum to: Folia Geobot \\ DOI 10.1007/S12224-013-9175-Z}

The online version of the original article can be found at http://dx.doi.org/10.1007/S12224-013-9175-z.

T. Fukami $(\bowtie)$

Department of Biology, Stanford University, Stanford, CA 94305, USA

e-mail: fukamit@stanford.edu

P. J. Bellingham • D. A. Peltzer

Landcare Research, PO Box 40, Lincoln 7640, New Zealand

L. R. Walker

School of Life Sciences, University of Nevada, 4505 Maryland Parkway, Las Vegas, NV 89154, USA 

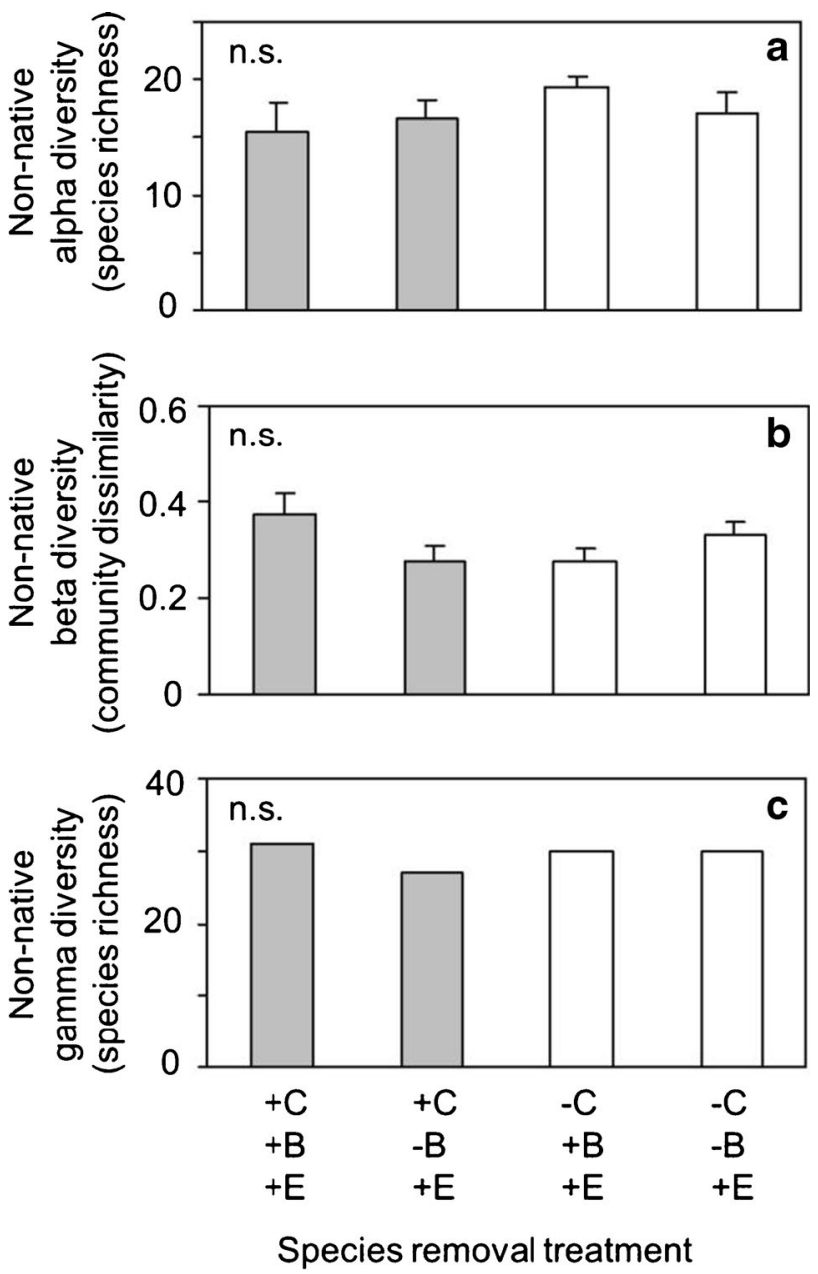

Fig. 4 Alpha, beta and gamma diversity of non-native plants at the end of the $4 \mathrm{yr}$ exclusion experiment (February 2006). Diversity was measured and tested for significant difference as in Fig. 2. Buddleja is not included in calculation of alpha, beta or gamma diversity. No significant effect of species removal treatment was detected (denoted by n.s.) 


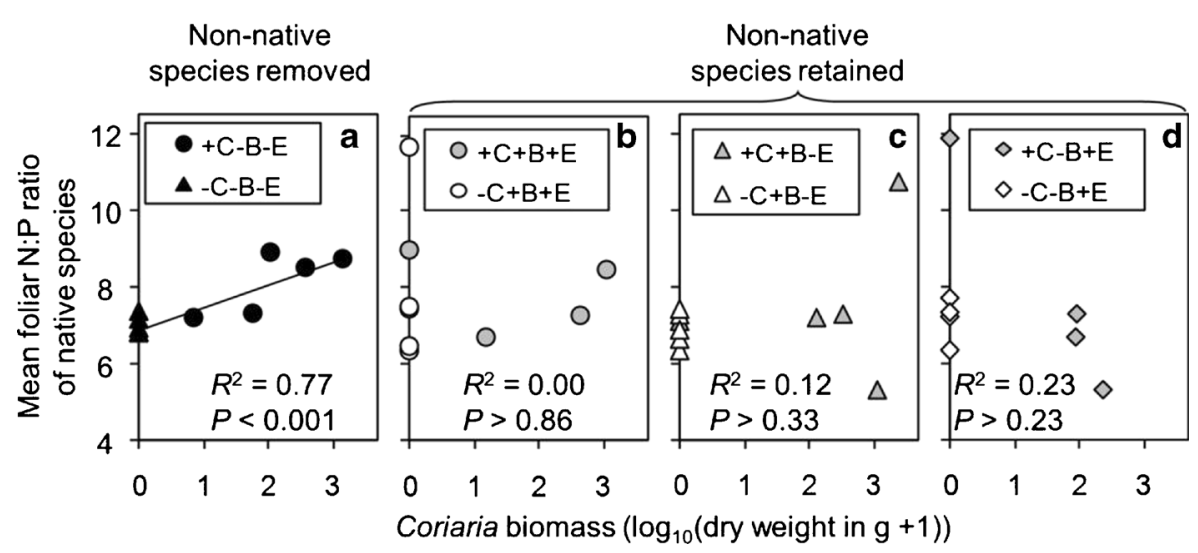

Fig. 5 Relationships between Coriaria biomass and mean foliar N:P of native species in plots where only native species were retained (a), where non-native species were also retained (b), where Buddleja (but no other non-native species) was also retained (c), and where non-native species other than Buddleja were also retained (d). Data points represent plots observed in February 2006. Regression line is shown where significant. Treatment symbols are as in Fig. 1

Published online: 1 April 2014 